\title{
PERAN KOMITE SEKOLAH DALAM PENYELENGGARAAN PENDIDIKAN SMK DI KABUPATEN LAMONGAN, JAWA TIMUR
}

\author{
Wahyu Dwi Mulyono \\ Program Studi Pendidikan Teknisi \& Kejuruan PP, UNY \\ wahyu_mulyono2@yahoo.co.id \\ Pardjono \\ Universitas Negeri Yogyakarta \\ jpardjono@yahoo.com
}

\begin{abstract}
Abstrak
Penelitian ini bertujuan untuk mengetahui peran komite sekolah dalam penyelenggaraan pendidikan SMK negeri dan SMK swasta di Kabupaten Lamongan sebagai badan pertimbangan, badan pendukung, badan pengontrol, dan badan penghubung.Penelitian ini merupakan penelitian evaluasi. Populasi sebanyak 61 SMK (enam SMK negeri dan 55 SMK swasta). Sampel sebanyak 42 SMK (empat SMK negeri dan 38 SMK swasta) ditentukan dengan teknik proportional random sampling. Pengumpulan data menggunakan kuesioner dengan skala Likert. Analisis data menggunakan teknik analisis deskriptif kuantitatif. Hasil penelitian ini adalah sebagai berikut. (1) Peran komite sekolah dalam penyelenggaraan pendidikan SMK negeri secara keseluruhan termasuk dalam kategori baik. Peran yang paling tinggi adalah sebagai badan pertimbangan, kemudian sebagai badan pendukung, dan sebagai badan penghubung, sedangkan peran yang paling rendah adalah sebagai badan pengontrol. (2) Peran komite sekolah dalam penyelenggaraan pendidikan SMK swasta secara keseluruhan termasuk dalam kategori baik. Peran yang paling tinggi adalah sebagai badan pendukung, kemudian sebagai badan penghubung, dan sebagai badan pertimbangan, sedangkan peran yang paling rendah adalah sebagai badan pengontrol.
\end{abstract}

Kata kunci: komite sekolah, SMK, badan pertimbangan, badan pendukung, badan pengontrol, badan penghubung

\section{THE ROLESOF THE SCHOOL COMMITTEE IN THE IMPLEMENTATION OF VOCATIONAL HIGH SCHOOL IN LAMONGAN REGENCY, EAST JAVA}

\begin{abstract}
This study is aimedat investigating the roles of the school committee in the implementation of state vocational high schools (VHS) and private VHSs in Lamongan Regency, as anadvisory agency, supporting agency, controlling agency, and mediator agency.This study isanevaluation. The population was 61 VHSs (six state VHSs and 55 private VHSs). A sample of 42 VHSs (four state VHSs and 48 private VHSs) was established using the proportional random sampling technique. The data collection used a questionnaire with Likert scale. The data analysis used the quantitative descriptive analysis.The results show as follows. (1) The overall role of the school committee in the implementation of state VHSs is in a good category. The highest is the role as the advisory agency, then the role as the supporting agency, and the role as the mediator agency, while the lowest is the role as the controlling agency. (2) The overall role of the school committee in the implementation of private VHSS is in a good category. The highest is the role as the supporting agency, then the role as the mediator agency, and the role as the advisory agency, while the lowest is the role as the controlling agency.
\end{abstract}

Keywords: school committee, vocational high schools, advisory agency, supporting agency, controlling agency, mediator agency 


\section{PENDAHULUAN}

Manajeman Berbasis Sekolah (MBS) merupakan model pengelolaan sekolah dengan memberikan kewenangan yang lebih besar pada tingkat sekolah untuk mengelola sekolahnya sendiri secara langsung (Nurkolis, 2005, p.11). Osorio, et al $(2009$, p.15) menjelaskan bahwa "SBM is the decentralization of authority from the central government to the school level" MBS merupakan pelimpahan kewenangan dari pemerintah pusat ke tingkat sekolah yang merupakan pemegang peranan utama dalam penyelenggaraan kebijakan pendidikan secara berkelanjutan. Di Nigeria terdapat istilah SBMC (school based management committe), Akinola (2009, p.2) menjelaskan bahwa SBMC adalah sebuah pendekatan untuk reformasi pendidikan yang memungkinkan sekolah secara mandiri untuk membuat keputusan berkaitan dengan keuangan, kurikulum, pengawasan, kebutuhan staf dan isu-isu lain yang berkaitan dengan proses belajar mengajar. Dalam Peraturan Pemerintah Nomor 19 tahun 2005 tentang Standar Nasional Pendidikan, pada pasal 49 ayat 1 disebutkan bahwa "Pengelolaan satuan pendidikan pada jenjang pendidikan dasar dan menengah menerapkan manajemen berbasis sekolah yang ditunjukkan dengan kemandirian, kemitraan, partisipasi, keterbukaan, dan akuntabilitas". MBS memberikan kewenangan kepada sekolah untuk mengambil berbagai kebijakan operasional sekolah yang dilakukan secara partisipatif dengan melibatkan stakeholder, antara lain guru, siswa, komite sekolah, dan tokoh masyarakat(Zajda, 2009, p.3).

Penyelenggaraan pendidikan harus melibatkan masyarakat untuk meningkatkan kualitas pendidikan. Partisipasi masyarakat di dalam pendidikan sudah ditetapkan didalam undang-undang, walaupun demikian dalam pelaksanaannya masih belum dapat tercapai. Hubungan masyarakat dengan sekolah masih dalam paradigma lama yaitu masih bersifat satu arah dan bersifat birokratis dan hierarkis. Masyarakat dan sekolah masih saling defensif. Sekolah masih memandang masyarakat sebagai orang lain atau pihak yang berada di luar sekolah (Depdiknas, 2007, pp.10-13). Masalah yang dihadapi dalam penyelenggaraan desentralisasi pendidikan kejuruan adalah lemahnya kapa- sitas kemitraan antara pendidikan kejuruan dengan masyarakat pada umumnya dan dunia usaha atau dunia industri (DU/DI) pada khususnya (Slamet, 2005, p.8). Pihak DU/ DI kurang dilibatkan dalam perencanaan pendidikan, padahal pendidikan kejuruan akan efektif apabila dimulai dan diakhiri oleh DU/ DI. Hanya pihak sekolah yang mempunyai peran aktif dalam pendidikan. Masyarakat masih belum aktif dalam kepentingan sekolah. Peran masyarakat terhadap penyelenggaraan pendidikan yang masih kurang, menyebabkan kualitas pendidikan yang diharapkan masih belum tercapai secara maksimal. Sebuah wadah atau lembaga dibutuhkan untuk menampung dan menyalurkan aspirasi masyarakat terhadap pendidikan.

Dalam Undang-Undang Nomor 20 Tahun 2003 tentang sistem pendidikan nasional, pada Pasal 56 ayat 1 menjelaskan bahwa masyarakat berperan dalam peningkatan mutu pelayanan pendidikan berupa perencanaan, pengawasan, dan evaluasi program pendidikan melalui dewan pendidikan dan komite sekolah. Dewan pendidikan dan komite sekolah dibentuk untuk meningkatkan partisipasi masyarakat dalam pendidikan. Dewan pendidikan dibentuk di setiap kabupaten atau kota, sedangkan komite sekolah dibentuk di setiap satuan pendidikan atau kelompok satuan pendidikan.

Kepmendiknas Nomor 044/U/2002 tentang dewan pendidikan dan komite sekolah, menjelaskan bahwa peran masyarakat dalam penyelenggarakan pendidikan akan semakin meningkat. Dewan pendidikan dan komite sekolah diharapkan dapat menyalurkan aspirasi masyarakat dengan baik. Melalui lembaga tersebut peran masyarakat akan semakin sentral dalam pendidikan (Depdiknas, 2002, p.7). Dalam Keputusan Menteri Pendidikan Nasional Nomor 044/U/2002 dijelaskan bahwa komite sekolah adalah badan mandiri yang mewadahi peran serta masyarakat untuk meningkatkan mutu, pemerataan, dan efisiensi pengelolaan pendidikan di satuan pendidikan. Komite sekolah yang dibentuk di setiap sekolah, merupakan lembaga strategis dan sangat penting dalam penyelenggaraan pendidikan di sekolah. Komite sekolah menurut Kim. A (2004, p.7) sebagai berikut. 
The school council is a collective decisionmaking body through broad participation of teachers, parents, and community leaders in the important decision-making process about school management.

Komite sekolah atau dewan sekolah adalah sebuah lembaga yang dibentuk untuk meningkatkan partisipasi dari para guru, orang tua, dan tokoh masyarakat dalam proses pengambilan keputusan tentang pengelolaan sekolah. Komite sekolah yang ada di luar negeri contohnya di Boston yaitu salah satu negara bagian di Amerika Serikat. Komite sekolah yang dikenal dengan nama The Boston School Commite.

The School Committee is responsible for: defining the vision, mission and goals of the Boston Public Schools; establishing and monitoring the annual operating budget; hiring, managing and evaluating the Superintendent; and setting and reviewing district policies and practices to support student achievement.(Boston Public School, 2013, p.1)

Komite sekolah adalah sebuah lembaga yang bertanggung jawab untuk menentukan visi, misi dan tujuan dari sekolah, menetapkan dan memantau anggaran operasional tahunan, menggunakan, mengelola dan mengevaluasi, dan menentukan serta mengkaji kebijakan dan praktik untuk mendukung prestasi siswa.

Berdasarkan uraian di atas, maka dapat disimpulkan bahwa komite sekolah adalah suatu lembaga mandiri yang dibentuk untuk mewadahi peran serta masyarakat di setiap satuan pendidikan dalam rangka meningkatkan kualitas pendidikan. Komite sekolah diharapkan dapat meningkatkan peran masyarakat dalam penyelenggaran sekolah, sehingga timbul rasa saling memiliki dan saling bertanggung jawab dalam kemajuan sekolah.

Komite sekolah harus bertumpu pada landasan partisipasi masyarakat dalam meningkatkan kualitas pelayanan dan hasil pendidikan di sekolah. Pembentukan komite sekolah harus memperhatikan pembagian peran sesuai posisi dan otonomi yang ada. Komite sekolah merupakan lembaga yang sangat penting bagi keberlangsungan sekolah. Khan et. al (2013, p.3) menjelaskan bahwa "School councils may facilitate head teachers in different academ$i c$, administrative and financial issues of the school". Komite sekolah mempunyai tanggung jawab dalam beberapa aspek yaitu administratif, akademik, dan finansial sekolah. Frontier School Division in Manitoba Canada (2011, p.21) menjelaskan bahwa komite sekolah terlibat dalam tiga aspek perencanaan sekolah yaitu mengidentifikasi topik, masalah dan prioritas untuk dimasukkan dalam rencana sekolah multi-tahun, rencana anggaran, rencana laporan sekolah dan laporan masyarakat. Peran komite sekolah dalam Kepmendiknas Nomor 044//U/2002 adalah pemberi pertimbangan (advisory agency) dalam penentuan dan pelaksanaan kebijakan pendidikan di satuan pendidikan, pendukung (supporting agency), baik yang berwujud finansial, pemikiran, maupun tenaga dalam penyelenggaraan pendidikan di satuan pendidikan, pengontrol (controlling agency) dalam rangka transparansi dan akuntabilitas penyelenggaraan dan keluaran pendidikan di satuan pendidikan, dan penghubung (mediator agency) antara pemerintah (eksekutif) dengan masyarakat di satuan pendidikan.

Komite sekolah sebagai badan pertimbangan berperan dalam penentuan dan pelaksanaan kebijakan pendidikan di tingkat satuan pendidikan, minimal dalam memberikan masukan, pertimbangan dan rekomendasi kepada satuan pendidikan untuk meningkatkan kualitas sekolah. (Haryadi, Meirawan, \& Rahadi, 2006, p.18). Zajda (2009, p.5) menjelaskan bahwa komite sekolah sangat dominan dalam pengambilan keputusan perencanaan sekolah khususnya dalam pengambilan keputusan tentang anggaran sekolah (approval of the school budget) dan pengambilan keputusan dalam rencana pengembangan sekolah (approval of the school improvement plan). Komite sekolah sebagai badan pertimbangan mempunyai tiga fungsi yaitu memberikan pertimbangan dalam perencanaan sekolah, pelaksanaan program pendidikan, dan pengelolaan sumber daya pendidikan. (Depdiknas, 2003c, p.21).

Komite sekolah sebagai badan pendukung berperan dalam memberikan dukungan terhadap sekolah dapat berwujud finansial, pemikiran, atau tenaga dalam penyelenggaraan, minimal dalam mendorong tumbuhnya perha- 
tian dan komitmen masyarakat terhadap penyelengaraan pendidikan yang bermutu (Haryadi, Meirawan, \& Rahadi, 2006, p.18). Department of Education, Newfoundland (2008, p.16) menjelaskan bahwa.

school councils shall participate in support and promote the plan approved by the board for improving teaching and learning in the school and approve and monitor activities for the raising of funds for the school.

Komite sekolah berperan dalam memberikan dukungan terhadap peningkatan kualitas pengajaran dan pembelajaran di sekolah dan memantau kegiatan penggalangan dana untuk sekolah. Ontario Ministry of Education (2002, p.1.1) menjelaskan bahwa komite sekolah memainkan peran penting dalam sistem pendidikan di Ontario. Komite sekolah memberikan dukungan dalam peningkatan prestasi belajar siswa dan kinerja sekolah. Komite sekolah sebagai badan pendukung mempunyai tiga fungsi yaitu memberikan dukungan dalam pengelolaan sumber daya sekolah, pengelolaan sarana dan prasarana sekolah, dan pengelolaan anggaran sekolah (Depdiknas, 2003c, p.25).

Department of Education, Newfoundland (2008, p.16) menjelaskan bahwa komite sekolah sebagai badan pengontrol melakukan perannya dalam dalam menyetujui dan memantau kegiatan penggalangan dana untuk sekolah, membantu dalam sistem monitoring dan evaluasi standar di sekolah, dan memantau pelaksanaan rekomendasi dalam laporan kinerja sekolah.

approve and monitor activities for the raising of funds for the school, assist in the system of monitoring and evaluating standards in the school, and monitor the implementation of recommendations in reports on the performance of the school.

Osorio, et al (2009, p.3) menjelaskan bahwa komite sekolah sebagai badan pengontrol berperan dalam memantau kinerja sekolah, seperti nilai ujian, kehadiran guru dan siswa, dan memeriksa laporan keuangan bulanan. Komite sekolah melakukan pengontrolan dalam rangka tranparansi dan akuntabilitas penyelenggaraan dan keluaran pendidikan minimal melakukan evaluasi dan pengawasan terhadap kebijakan, program, penyelenggaraan, dan keluaran pendidikan dari satuan pendidikan (Haryadi, Meirawan \& Rahadi, 2006, p.19). Komite sekolah sebagai badan pengontrol mempunyai tiga fungsi yaitu mengontrol perencanaan pendidikan di sekolah, memantau pelaksanaan program sekolah, dan memantau output pendidikan (Depdiknas, 2003c, p.31).

Khan et. al (2013, p.3) menjelaskan bahwa komite sekolah di Pakistan sebagai badan penghubung berperan dalam membantu pertemuan antara wali siswa dengan guru dan mengadakan pertemuan rutin setiap bulan dengan semua anggota komite sekolah, sebagai berikut.

Responsibilities of school Councils in Pakistan are to help them in parent teacher meeting, and to hold one meeting of school council every month so that there should be at least 10 meeting in year.

Ontario Ministry of Education (2002, p.1.1) menjelaskan peran komite sekolah sebagai berikut.

School councils play a vital role in the education system in Ontario. They provide a forum through which parents and other members of school communities can contribute to improving student achievement and school performance.

Komite sekolah mempunyai peran penting dalam sistem pendidikan. Komite sekolah menyediakan sebuah forum di mana orang tua dan anggota lain dari komunitas sekolah dapat berkontribusi terhadap peningkatan prestasi belajar siswa dan kinerja sekolah. Zajda (2009, p.9) menjelaskan lebih jauh lagi tentang peran komite sekolah sebagai badan penghubung yaitu "Engaging parents, carers and the community in education, including community and business partnerships". Komite sekolah sebagai badan penghubung meningkatkan keterlibatan orang tua, wali dan masyarakat dalam pendidikan, termasuk masyarakat dan perusahaan mitra sekolah atau DU/DI. Haryadi, Meirawan, \& Rahadi (2006, p.19) menjelaskan bahwa komite sekolah berperan sebagai mediator antara pemerintah (eksekutif) dengan masyarakat di satuan pendidikan, meliputi kegiatan sebagai melakukan kerjasama dengan masyarakat baik perorangan, 
organisasi pemerintah dan kemasyarakatan untuk penyelenggaraan pendidikan dan pembelajaran yang bermutu, dan menampung dan menganalisis aspirasi, ide, tuntutan dan berbagai kebutuhan pendidikan yang diajukan oleh masyarakat. Komite sekolah sebagai badan penghubung mempunyai tiga fungsi yaitu menjadi penghubung antara masyarakat dengan sekolah dalam perencanaan pendidikan, pelaksanaan program sekolah, dan pengelolaan sumber daya pendidikan. (Depdiknas, 2003c, p.35).

Permasalahan yang muncul adalah komite sekolah belum dapat menjalankan perannya dengan baik, kehadiran komite sekolah dipandang sebagai badan legalitas (stempel) yang mengesahkan berbagai pungutan dana oleh pihak sekolah. Di samping itu, pihak-pihak yang berkepentingan dengan pendidikan kurang mengetahui tentang fungsi dan peran komite sekolah. Komite sekolah dianggap sama saja dengan badan pembantu penyelenggara pendidikan (BP3). Hal ini menunjukkan sosialisasi komite sekolah belum terlaksana dengan baik kepada masyarakat bahkan kepada komite sekolah itu sendiri. Komite sekolah yang telah dibentuk itu pun banyak yang belum memiliki anggaran dasar (AD) dan anggaran rumah tangga (ART) yang disusun berdasarkan aspirasi orangtua dan masyarakat sebagai komponen utama stakeholder pendidikan (Depdiknas, 2003a, p.2). Hasil kajian yang dilakukan oleh Nurlaela, et.al (2011, p.23) mengenai peran komite sekolah dalam membangun kemitraan antara DU/DI dengan Sekolah Menengah Kejuruan (SMK), menemukan bahwa peran komite sekolah masih kurang, baik sebagai lembaga pemberi pertimbangan, pendukung, pengontrol, dan sebagai lembaga mediator. Alip \& Soenarto (2008, p.10) juga menjelaskan bahwa peran komite sekolah yang paling menonjol adalah sebagai badan pendukung dan yang paling lemah adalah sebagai badan pengontrol, sedangkan Nurdin Hidayat (2010, pp.139-140) menjelaskan bahwa peran komite sekolah yang paling lemah adalah sebagai badan pengontrol dan paling tinggi adalah sebagai badan pertimbangan. Penelitian yang dilakukan oleh Armansyah (2009, p.83) menjelaskan bahwa komite sekolah dalam melaksanaan perannya hanya sebagai pemberi pertimbangan dan pengawasan yang lebih utama, sedangkan peran- nya sebagai pendukung dan mediator belum sepenuhnya terlaksana. Hasil pra survei pada SMK di Kabupaten Lamongan juga menunjukkan bahwa komite sekolah masih kurang aktif. Komite sekolah hanya berperan dalam hal pendanaan sekolah. Komite sekolah belum terlibat dalam pembelajaran dan program-program sekolah.

Melihat kondisi dan keprihatinan terhadap kualitas pendidikan dengan tidak optimalnya peran komite sekolah, maka perlu berbagai strategi untuk melakukan pemberdayaan komite sekolah. Mulai tahun 2011 pemerintah melalui Direktorat Jenderal Pendidikan Menengah Kementerian Pendidikan dan Kebudayaan telah memberikan bantuan sosial kepada komite sekolah. Pemberian bantuan sosial tersebut dimaksudkan untuk memperkuat kelembagaan komite sekolah sebagai bagian dari program pemberdayaan masyarakat dalam rangka peningkatan mutu pendidikan. Pada tahun anggaran 2013 Direktorat Jenderal Pendidikan Menengah Kementerian Pendidikan dan Kebudayaan mengalokasikan Bantuan Sosial pemberdayaan komite sekolah yang dikelola Bagian Keuangan Sekretariat Direktorat Jenderal Pendidikan Menengah dengan nilai bantuan sosial Rp15.000.000,- setiap komite sekolah (Kemdikbud, 2013, p.1). Sejalan dengan pemberian bantuan sosial tersebut, maka perlu dilakukan penilaian terhadap peran komite sekolah. Komite sekolah yang mempunyai program kerja dan peran yang baik yang layak mendapatkan bantuan sosial, jangan sampai ada komite sekolah yang hanya nama, tetapi tidak ada hasil kerjanya, pembentukannya hanya sebagai syarat untuk memperoleh dana bantuan semata.

Berangkat dari uraian di atas, maka penelitian ini berfokus pada peran komite sekolah dalam penyelenggaraan SMK di Kabupaten Lamongan, Jawa Timur. Penelitian tentang peran komite sekolah perlu dilakukan untuk mengetahui pelaksanakan peran komite sekolah di masing-masing SMK (SMK negeri dan SMK swasta) sebagai badan pertimbangan, badan pendukung, badan pengontrol, dan badan penghubung, sehingga dapat menjadi informasi yang sangat berguna untuk merencanakan program pemberdayaan dalam peningkatan mutu pendidikan melalui komite sekolah. 
Tabel 1. Kriteria Penilaian Masing-Masing Variabel

\begin{tabular}{lll}
\hline No. & Rentang Skor & Kriteria \\
\hline 1. & $\mathrm{X}>\mathrm{Mi}+1,5 \mathrm{SDi}$ & Sangat baik \\
2. & $\mathrm{Mi}+0,5 \mathrm{SDi}<\mathrm{X} \leq \mathrm{Mi}+1,5 \mathrm{SDi}$ & Baik \\
3. & $\mathrm{Mi}-0,5 \mathrm{SDi}<\mathrm{X} \leq \mathrm{Mi}+0,5 \mathrm{SDi}$ & Cukup \\
4. & $\mathrm{Mi}-1,5 \mathrm{SDi}<\mathrm{X} \leq \mathrm{Mi}-0,5 \mathrm{SDi}$ & Kurang \\
5. & $\mathrm{X} \leq \mathrm{Mi}-1,5 \mathrm{SDi}$ & Sangat Kurang \\
\hline
\end{tabular}

(Anas Sudijono, 2006, p.453)

\section{Keterangan:}

$\mathrm{Mi}=$ Mean ideal

$\mathrm{SDi}=$ Standar deviasi ideal

$\mathrm{X}=$ Skor rata-rata

$\mathrm{Mi}=1 / 2($ skor maksimal + skor minimal $)$

$\mathrm{SDi}=1 / 6$ (skor maksimal - skor minimal)

Skor Maksimal $=\sum$ butir instrumen $\mathrm{x}$ skor tertinggi

Skor minimal $=\sum$ butir instrumen $\mathrm{x}$ skor terendah

\section{METODE PENELITIAN}

Jenis penelitian ini adalah penelitian evaluasi. Penelitian ini memberikan gambaran dan evaluasi terhadap hasil pelaksanaan peran komite sekolah terhadap penyelenggaran pendidikan SMK di Kabupaten Lamongan Metode penelitian menggunakan deskriptif kuantitatif.

Tempat penelitian ini adalah SMK di Kabupaten lamongan, Jawa Timur. Penelitian ini dilaksanakan pada bulan Januari 2014 sampai dengan bulan Maret 2014.

Populasi dalam penelitian ini adalah 61 SMK (enam SMK negeri dan 55 SMK swasta). Sampel sebanyak 42 SMK (empat SMK negeri dan 38 SMK swasta) ditentukan dengan teknik proportional random sampling. Responden dari masing-masing SMK adalah kepala sekolah, wakil kepala sekolah, guru, dan komite sekolah.

Sebelum dilaksanakan penelitian dilakukan dulu penyusunan instrumen berupa kuisoner. Untuk mendapatkan kuisoner yang baik maka dilakukan uji validitas dan reliabilitas. Validitas teoritis dengan rasional judgementexpert, kemudian dilakukan uji coba kelapangan. Reliabilitas instrumen dalam penelitian ini adalah dengan uji statistik Cronbach Alpha $(\alpha)$.

Prosedur penelitian dilakukan dengan melakukan pengumpulan data menggunakan kuesioner dengan skala Likert yang terdiri dari lima pilihan jawaban yang digunakan untuk memperoleh informasi dari responden tentang peran komite sekolah dalam penyelenggaraan SMK, kemudian data yang sudah diperoleh dianalisis data menggunakan teknik analisis deskriptif kuantitatif yaitu dengan cara menganalisis data dengan statistik deskriptif kemudian mendeskripsikannya dalam bentuk tabel dan grafik. Setelah itu melakukan penilaian terhadap peran komite sekolah yang dilakukan dengan membandingkan skor hasil penilaian dengan skor kriteria berdasarkan kurva normal.

\section{HASIL PENELITIAN DAN PEMBAHASAN}

Subjek penelitian ini adalah komite sekolah SMK di Kabupaten lamongan, Jawa Timur. SMK di Kabupaten Lamongan berjumlah 61 SMK yang terdiri dari 6 SMK negeri dan 55 SMK swasta yang tersebar di 27 kecamatan. Jumlah sampel dari penelitian ini adalah 42 SMK yang terdiri dari 4 SMK negeri dan 38 SMK swasta. Data penelitian diperoleh dari hasil kuisoner yang sudah diisi oleh responden dari masing-masing SMK. Data yang terkumpul dari responden sebanyak 298. Data dari SMK negeri terkumpul sebanyak 32 responden, sedangkan data dari SMK swasta terkumpul sebanyak 266 responden. 
Pada penelitian ini terdapat empat variabel yaitu peran komite sekolah sebagai badan pertimbangan (V1)badan pendukung (V2), badan pengontrol (V3), dan badan penghubung (V4). Sebelum dilakukan analisis lebih lanjut, akan ditetapkan terlebih dahulu nilai batasan untuk menentukan skor kriteria dari masing-masing variabel. Setelah itu, dibuat tabel kriteria dari masing-masing variabel.

Tabel 2. Nilai Batasan dalam Menentukan Kriteria dari Masing-Masing Variabel

\begin{tabular}{lllll}
\hline Hasil Analisis & V1 & V2 & V3 & V4 \\
\hline Skor tertinggi angket & 5 & 5 & 5 & 5 \\
Skor terendah angket & 1 & 1 & 1 & 1 \\
Skor maksimal & 70 & 65 & 75 & 75 \\
Skor minimal & 14 & 13 & 15 & 15 \\
Mean ideal (Mi) & 42 & 39 & 45 & 45 \\
Standar Deviasi ideal (SDi) & 9,3 & 8,67 & 10 & 10 \\
\hline
\end{tabular}

Berdasarkan nilai batasan yang telah ditentukan pada tabel $2 \mathrm{di}$ atas, maka dapat dibuat tabel skor kriteria dari masing-masing variabel di bawah ini.

Tabel 3. Kriteria Peran Komite Sekolah sebagai Badan Pertimbangan (V1)

\begin{tabular}{ll}
\hline Rentang Skor & Kriteria \\
\hline $\mathrm{X}>56$ & Sangat baik \\
$47<\mathrm{X} \leq 56$ & Baik \\
$37<\mathrm{X} \leq 47$ & Cukup \\
$28<\mathrm{X} \leq 37$ & Kurang \\
$\mathrm{X} \leq 28$ & Sangat Kurang \\
\hline
\end{tabular}

Tabel 4. Kriteria Peran Komite Sekolah sebagai Badan Pendukung (V2)

\begin{tabular}{ll}
\hline Rentang Skor & Kriteria \\
\hline$X>52$ & Sangat baik \\
$43,3<X \leq 52$ & Baik \\
$34,7<X \leq 43,3$ & Cukup \\
$26<X \leq 34,7$ & Kurang \\
$X \leq 26$ & Sangat Kurang \\
\hline
\end{tabular}

Untuk variabel badan pengontrol (V3) dan badan penghubung (V4) mempunyai jumlah butir yang sama, sehinggamempunyai skor yang sama, untuk itu, ditetapkan dalam satu skor kriteria yaitu pada tabel 5 di bawah ini.

Tabel 5. Kriteria Peran Komite Sekolah sebagai Badan Pengontrol (V3) dan Badan Penghubung (V4)

\begin{tabular}{ll}
\hline Rentang Skor & Kriteria \\
\hline$X>60$ & Sangat baik \\
$50<X \leq 60$ & Baik \\
$40<X \leq 50$ & Cukup \\
$30<X \leq 40$ & Kurang \\
$X \leq 30$ & Sangat Kurang \\
\hline
\end{tabular}

Berdasarkan data penelitian dan tabel skor kriteria maka hasil penelitian dan pembahasan dari masing-masing variabel dalam penelitian ini adalah sebagai berikut.

\section{Peran Komite Sekolah dalam Penyeleng- garaan Pendidikan di SMK Negeri}

Peran komite sekolah dalam penyelenggaraan pendidikan SMK negeri di Kabupaten Lamongan dijelaskan dalam tabel 6 di bawah ini.

Tabel 6. Peran Komite Sekolah dalam Penyelenggaraan Pendidikan SMK Negeri di Kabupaten Lamongan

\begin{tabular}{lcccc}
\hline Variabel & Skor Maks & Skor Rata-rata & $\mathbf{( \% )}$ & Kategori \\
\hline Badan Pertimbangan (V1) & 70 & 56,84 & 81,21 & Sangat Baik \\
Badan Pendukung (V2) & 65 & 51,59 & 79,38 & Baik \\
Badan Pengontrol (V3) & 75 & 58,75 & 78,33 & Baik \\
Badan Penghubung (V4) & 75 & 59,19 & 78,92 & Baik \\
\hline Rata-rata & 71,25 & 56,59 & 79,46 & Baik \\
\hline
\end{tabular}




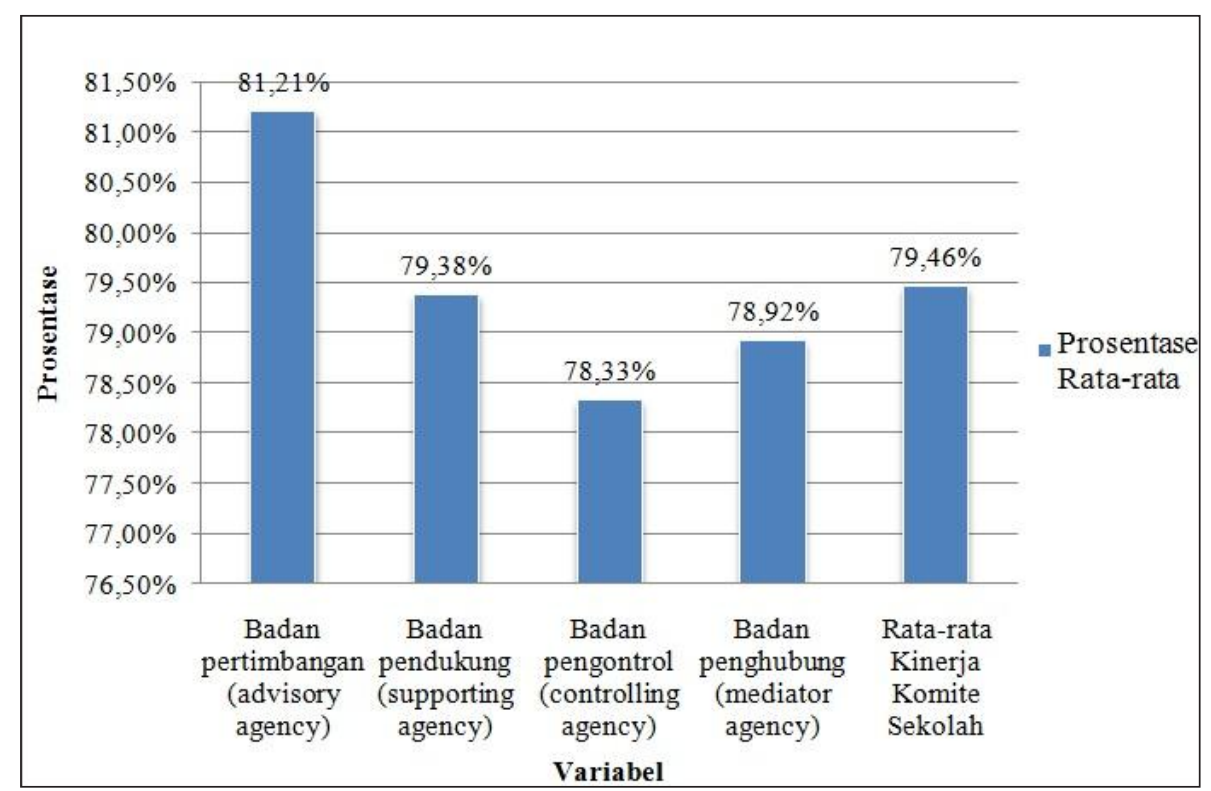

Gambar 1. Perbandingan Peran Komite Sekolah dalam Penyelenggaraan Pendidikan SMK Negeri di Kabupaten Lamongan

Berdasarkan tabel 6 tentang peran komite sekolah dalam penyelenggaraan SMK negeri di Kabupaten Lamongan, untuk membandingkan antar variabel, maka dibuat diagram dalam gambar 1.

Berdasarkan pada tabel 6 dan gambar 1 tentang peran komite sekolah dalam penyelenggaraan pendidikan SMK negeri di Kabupaten Lamongan, dapat dijelaskan bahwa secara keseluruhan peran komite sekolah termasuk dalam kategori baik dengan skor rata-rata rata-rata sebesar 56,59 dan prosentase mencapai $79,25 \%$ dari skor maksimal.

Variabel yang paling menonjol adalah sebagai badan pertimbangan yang mencapai skor rata-rata 56,84 dengan prosentase $81,21 \%$ dari skor maksimal. Skor yang paling rendah ditunjukkan oleh variabel badan pengontrol dengan skor rata-rata 58,75 dan prosentase rata-rata $78,33 \%$ dari skor maksimal. Sedangkan, variabel badan pendukung mempunyai skor rata-rata 51,59 dengan prosentase 79,38\% dari skor maksimal dan variabel badan penghubung mempunyai skor rata-rata 59,19 dengan prosentase $78,92 \%$ dari skor maksimal.

Berdasarkan data tersebut, maka komite sekolah dalam perannya lebih aktif dalam penyelenggaraan pendidikan berupa memberikan pertimbangan dan mendukung pelaksanaan program sekolah. Sebagai mitra dari sekolah, komite sekolah sudah berjalan dengan baik, tetapi sebagai badan pengontrol komite sekolah masih perlu ditingkatkan. Komite sekolah harus lebih aktif dalam memantau dan mengevaluasi peran dari sekolah, karena komite sekolah mempunyai wewenang dalam meminta pertanggungjawaban dari pihak sekolah atas seluruh kegiatan yang dilaksanakan dalam program sekolah. Komite sekolah juga harus lebih aktif dalam mengevaluasi penggunaan anggaran sekolah, sehingga dapat meningkatkan efektifitas penggunaan anggaran sekolah. Komite sekolah sebagai badan penghubung juga harus ditingkatkan. Peran komite sekolah di SMK negeri sebagai badan penghubung mendapatkan nilai terendah disamping sebagai badan pengontrol. Komunikasi harus ditingkatkan antara masyarakat dengan pihak sekolah, sehingga tercipta transparansi dalam berbagai hal, termasuk dalam penggunaan anggaran, pembangunan sarana/prasarana, dan keluaran pendidikan. Sekolah harus terbuka kepada pihak masyarakat sebagai bagian dari warga sekolah, sehingga apabila ada permasalahan yang menyangkut penyelenggaraan pendidikan di sekolah dapat diselesaikan bersama-sama secara musyawarah antara pihak sekolah dengan masyarakat. Komunikasi yang aktif dapat meningkatkan rasa kepemilikan 
sekolah, sehingga dapat memanfaatkan secara maksimal sumber daya yang ada untuk kemajuan sekolah.

Berdasarkan hasil penelitian, maka peran komite sekolah dalam penyelenggaraan pendidikan SMK negeri harus dipertahankan dalam perannya sebagai badan pertimbangan dan badan pendukung, sedangkan sebagai badan pengontrol dan badan penghubung harus ditingkatkan.

Komite sekolah di SMK negeri sebagai badan pertimbangan mempunyai peran tertinggi dalam memberikan pertimbangan terhadap penyelenggarakan rapat RAPBS sesuai agenda tahunan sekolah, sedangkan peran terendah ditunjukkan dalam memberikan pertimbangan pada proses rekruitmen tenaga pendidik. Hal tersebut menunjukkan bahwa komite sekolah lebih aktif terlibat dalam hal yang berkaitan dengan pendanaan sekolah, dan kurang begitu terlibat dalam proses rekruitmen tenaga pendidik.Hal tersebut sesuai dengan pendapat Zajda (2009, p.5) yaitu komite sekolah sangat dominan dalam pengambilan keputusan perencanaan sekolah khususnya dalam pengambilan keputusan tentang anggaran sekolah (approval of the school budget).

Komite sekolah di SMK negeri sebagai badan pendukung mempunyai peran tertinggi dalam mendukung pemberian beasiswa bagi siswa yang berasal dari keluarga tidak mampu dan siswa yang berprestasi. Sedangkan, peran terendah adalah membantu dalam rekrutmen tenaga kependidikan untuk mengisi kekurangan di sekolah. Hal tersebut menunjukkan bahwa komite sekolah sangat peduli terhadap siswa yang berprestasi dan berasal dari keluarga yang tidak mampu, sehingga memberikan dukungan dalam memberikan beasiswa pendidikan. Hasil penelitian menunjukkan kesesuaian dengan pendapat Khan et. al $(2013$, p.3) yaitu komite sekolah berperan untuk mengurangi angka putus sekolah dengan memberikan kesadaran kepada orang tua tentang pentingnya pendidikan dan memberikan beasiswa.

Komite sekolah di SMK negeri sebagai badan pengontrol mempunyai peran tertinggi dalammemantau tingkat kelulusan siswa, sedangkan peran terendah adalah dalam memeriksa pelaksanaan organisasi sekolah. Hal tersebut menunjukkan bahwa komite sekolah sangat peduli terhadap keluaran pendidikan berupa tingkat kelulusan siswa dan nilai hasil belajar siswa. Komite sekolah kurang peduli terhadap pelaksanaan organisasi sekolah, yang merupakan salah satu hal penting dalam pelaksanaan pendidikan di sekolah.

Komite sekolah di SMK negeri sebagai badan penghubung mempunyai peran tertinggi dalammensosialisasikan kebijakan dan program sekolah kepada masyarakat, sedangkan nilai terendah adalah dalam mengadakan pelatihan untuk meningkatkan kualitas tenaga kependidikan di sekolah. Pelatihan terhadap tenaga kependidikan belum mendapat perhatian dari komite sekolah SMK negeri. Hasil penelitian menunjukkan bahwa komite sekolah aktif dalam menjalin komunikasi antara masyarakat dengan pihak sekolah, khususnya dalam mensosialisasikan kebijakan dan program sekolah. Hal tersebut sesuai dengan penjelasan Zajda (2009, p.9) bahwa komite sekolah meningkatkan keterlibatan orang tua, wali dan masyarakat dalam pendidikan, termasuk masyarakat dan perusahaan mitra sekolah atau DU/DI.

\section{Peran Komite Sekolah dalam Penyeleng- garaan Pendidikan di SMK Swasta}

Peran komite sekolah dalam penyelenggaraan pendidikan SMK swasta di Kabupaten Lamongan sebagai badan pertimbangan, badan pendukung, badan pengontrol, dan badan penghubung dijelaskan dalam tabel 7 di bawah ini.

Berdasarkan tabel 7 tentang peran komite sekolah dalam penyelenggaraan SMK swasta di Kabupaten Lamongan, untuk membandingkan antar variabel badan pertimbangan, badan pendukung, badan pengontrol, dan badan penghubung, maka dibuat diagram dalam gambar 2 .

Berdasarkan pada tabel 7 dan gambar 2 tentang peran komite sekolah dalam penyelenggaraan pendidikan SMK Swasta di Kabupaten Lamongan, dapat dijelaskan bahwa secara keseluruhan peran komite sekolah termasuk dalam kategori baik dengan skor rata-rata rata-rata sebesar 50,02 dan prosentase mencapai 70,27\% dari skor maksimal rata-rata.

Variabel yang paling menonjol adalah sebagai badan pendukung yang mencapai skor 
Tabel 7. Peran Komite Sekolah dalam Penyelenggaraan Pendidikan SMK Swasta di Kabupaten Lamongan

\begin{tabular}{lcccc}
\hline Variabel & Skor Maks & Skor Rata-rata & $\mathbf{( \% )}$ & Kategori \\
\hline Badan Pertimbangan (V1) & 70 & 49,23 & 70,32 & Baik \\
Badan Pendukung (V2) & 65 & 47,07 & 72,42 & Baik \\
Badan Pengontrol (V3) & 75 & 50,09 & 66,78 & Baik \\
Badan Penghubung (V4) & 75 & 53,67 & 71,55 & Baik \\
Rata-rata & 71,25 & 50,02 & 70,27 & Baik \\
\hline
\end{tabular}

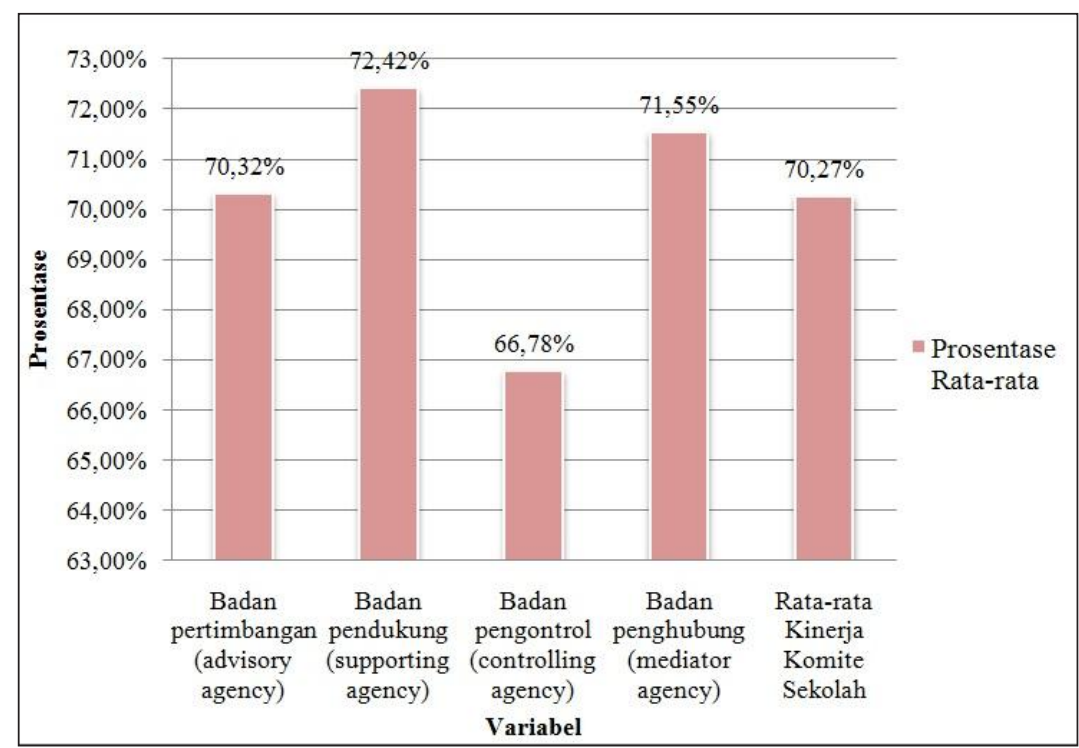

Gambar 2. Perbandingan Peran Komite Sekolah dalam Penyelenggaraan Pendidikan SMK Swasta di Kabupaten Lamongan

rata-rata 47,07 dengan prosentase $72,42 \%$ dari skor maksimal. Skor yang paling rendah ditunjukkan oleh variabel badan pengontrol dengan skor rata-rata 50,09 dan prosentase rata-rata $66,78 \%$ dari skor maksimal. Sedangkan, variabel badan pertimbangan mempunyai skor rata-rata 49,23 dengan prosentase 70,32\% dari skor maksimal dan variabel badan penghubung mempunyai skor rata-rata 53,67 dengan prosentase $71,55 \%$ dari skor maksimal.

Berdasarkan data tersebut, maka komite sekolah dalam perannya lebih aktif dalam penyelenggaraan pendidikan berupa memberikan dukungan dalam pelaksanaan program disekolah dan menjadi penghubung antara masyarakat dengan sekolah. Sebagai mitra dari sekolah komite sekolah sudah berjalan dengan baik, khususnya dalam mendukung program-program sekolah, tetapi sebagai badan pengontrol komite sekolah masih perlu ditingkatkan. Komite sekolah harus lebih aktif dalam memantau dan mengevaluasi peran dari sekolah. Komite sekolah juga harus lebih aktif dalam mengevaluasi penggunaan anggaran sekolah, sehingga dapat meningkatkan efektifitas penggunaan anggaran sekolah. Komite sekolah sebagai badan pertimbangan juga harus ditingkatkan. Peran sebagai badan pertimbangan mendapatkan nilai terendah disamping sebagai badan pengontrol. Komite sekolah harus dilibatkan secara aktif dalam setiap perencanaan sekolah. Komite sekolah sebagai badan pertimbangan harus ditingkatkan, khususnya dalam memberikan masukan dalam setiap kebijakan tentang program sekolah. Kebijakan yang diambil secara bersama-sama antara pihak sekolah dengan masyarakat dapat meningkatkan rasa saling tanggungjawab terhadap pendidikan disekolah, sehingga dapat meningkatkan rasa kepemilikan sekolah. 
Berdasarkan hasil penelitian, maka peran komite sekolah dalam penyelenggaraan pendidikan SMK swasta harus dipertahankan dalam perannya sebagai badan pendukung dan badan penghubung, sedangkan sebagai badan pengontrol dan badan pertimbangan harus ditingkatkan.

Komite sekolah di SMK swasta sebagai badan pertimbangan mempunyaiperan tertinggi dalam memberikan pertimbangan kepada sekolah dalam penyusunan visi dan misi sekolah, sedangkan peran terendah adalah memberikan pertimbangan dalam pelaksanaan evaluasi belajar di sekolah. Hal tersebut menunjukkan bahwa komite sekolah lebih aktif terlibat dalam perencanaan sekolah, dan kurang begitu terlibat dalam proses pembelajaran di sekolah. Boston Public School (2013, p.1) menjelaskan bahwa komite sekolah berwenang dalam menentukan visi, misi, dan tujuan sekolah, menetapkan anggaran tahunan sekolah, dan memberikan kebijakan sekolah untuk meningkatkan prestasi siswa. Komite sekolah sebagai badan pertimbangan seharusnya tidak hanya aktif dalam perencanaan sekolah, melainkan terlibat juga dalam memberikan pertimbangan pada proses pembelajaran di sekolah yang meliputi kegiatan perencanaan, pelaksanaan, dan evaluasi pembelajaran.

Komite sekolah di SMK swasta sebagai badan pendukung mempunyai Peran tertinggi adalah dalammendukung pemberian beasiswa bagi siswa yang berasal dari keluarga tidak mampu dan siswa yang berprestasi. Sedangkan, peran terendah adalah membantu dalam rekrutmen tenaga kependidikan untuk mengisi kekurangan di sekolah. Hal tersebut menunjukkan bahwa komite sekolah sangat peduli terhadap siswa yang berprestasi dan berasal dari keluarga yang tidak mampu, sehingga memberikan dukungan dalam memberikan beasiswa. Rendahnya peran dalam membantu rekruitmen tenaga kependidikan kemungkinan disebabkan karena sudah tercukupinya tenaga kependidikan yang ada di sekolah, sehingga belum membutuhkan untuk melakukan rekruitmen tenaga pendidik baru

Komite sekolah di SMK swasta sebagai badan pengontrol mempunyai peran tertinggi adalah dalam memantau tingkat kelulusan siswa, sedangkan peran terendah adalah dalam memberikan pengawasan terhadap perencanaan penggunaan anggaran pendidikan yang ada di sekolah. Hal tersebut menunjukkan bahwa komite sekolah sangat peduli terhadap keluaran pendidikan berupa tingkat kelulusan siswa dan nilai hasil belajar siswa. Pengawasan terhadap perencanaan penggunaan anggaran pendidikan masih rendah dikarenakan sebagian besar anggota komite sekolah adalah guru, sehingga lebih aktif dalam pengelola dan pendukung dalam pelaksanaan program dan penggunaan anggaran, tetapi masih kurang berfungsi sebagai pengawas atau pengontrol penggunaan anggaran.

Komite sekolah di SMK swasta sebagai badan penghubung mempunyai peran tertinggi adalah dalammenyalurkan aspirasi masyarakat untuk perencanaan pendidikan. Sedangkan, nilai terendah adalah dalam membina kerjasama dengan perguruan tinggi dalam program pengalaman lapangan (PPL) atau pendamping SMK. Zajda (2009, p.9) menjelaskan bahwa komite sekolah sebagai badan penghubung meningkatkan keterlibatan orang tua, wali dan masyarakat dalam pendidikan, termasuk masyarakat dan perusahaan mitra sekolah atau DU/DI. Berdasarkan pendapat tersebut, maka menunjukkan kesesuaian dengan peran komite seolah sebagai badan penghubung dalam menyalurkan aspirasi masyarakat untuk perencanaan pendidikan. Rendahnya peran komite sekolah dalam menjalin hubungan dengan peguruan tinggi dalam PPL atau pendamping SMK, dikarenakan SMK lebih berorientasi ke dunia kerja, sehingga kerjasama lebih intensif dilakukan dengan DU/DI.

\section{Perbandingan Peran Komite Sekolah dalam Penyelenggaraan Pendidikan SMK Negeri dan SMK Swasta}

Perbandingan antara peran komite sekolah dalam peyelenggaraan pendidikan di SMK negeri dan SMK swasta dalam perannya sebagai badan pertimbangan (advisory agency), badan pendukung (supporting agency), badan pengontrol (controlling agency), dan badan penghubung, dan badan penghubung (mediator agency) sebagaimana pada tabel 8dan gambar 3 . 


\begin{tabular}{|c|c|c|c|c|c|c|c|c|c|}
\hline \multirow[b]{2}{*}{ No } & \multirow[b]{2}{*}{ Variabel } & \multicolumn{4}{|c|}{ SMK Negeri } & \multicolumn{4}{|c|}{ SMK Swasta } \\
\hline & & $\begin{array}{l}\text { Skor } \\
\text { Maks }\end{array}$ & $\begin{array}{c}\text { Skor } \\
\text { Rata- } \\
\text { rata }\end{array}$ & $(\%)$ & Ket & $\begin{array}{l}\text { Skor } \\
\text { Maks }\end{array}$ & $\begin{array}{c}\text { Skor } \\
\text { Rata- } \\
\text { rata }\end{array}$ & $(\%)$ & Ket \\
\hline 1 & Badan pertimbangan & 70 & 56,84 & 81,21 & Sangat Baik & 70 & 49,23 & 70,32 & Baik \\
\hline 2 & Badan pendukung & 65 & 51,59 & 79,38 & Baik & 65 & 47,07 & 72,42 & Baik \\
\hline 3 & Badan pengontrol & 75 & 58,75 & 78,33 & Baik & 75 & 50,09 & 66,78 & Baik \\
\hline 4 & Badan penghubung & 75 & 59,19 & 78,92 & Baik & 75 & 53,67 & 71,55 & Baik \\
\hline $\begin{array}{l}\text { Rat: } \\
\text { Sek }\end{array}$ & $\begin{array}{l}\text {-rata Peran Komite } \\
\text { glah }\end{array}$ & 71,25 & 56,59 & 79,46 & Baik & 71,25 & 50,02 & 70,27 & Baik \\
\hline
\end{tabular}

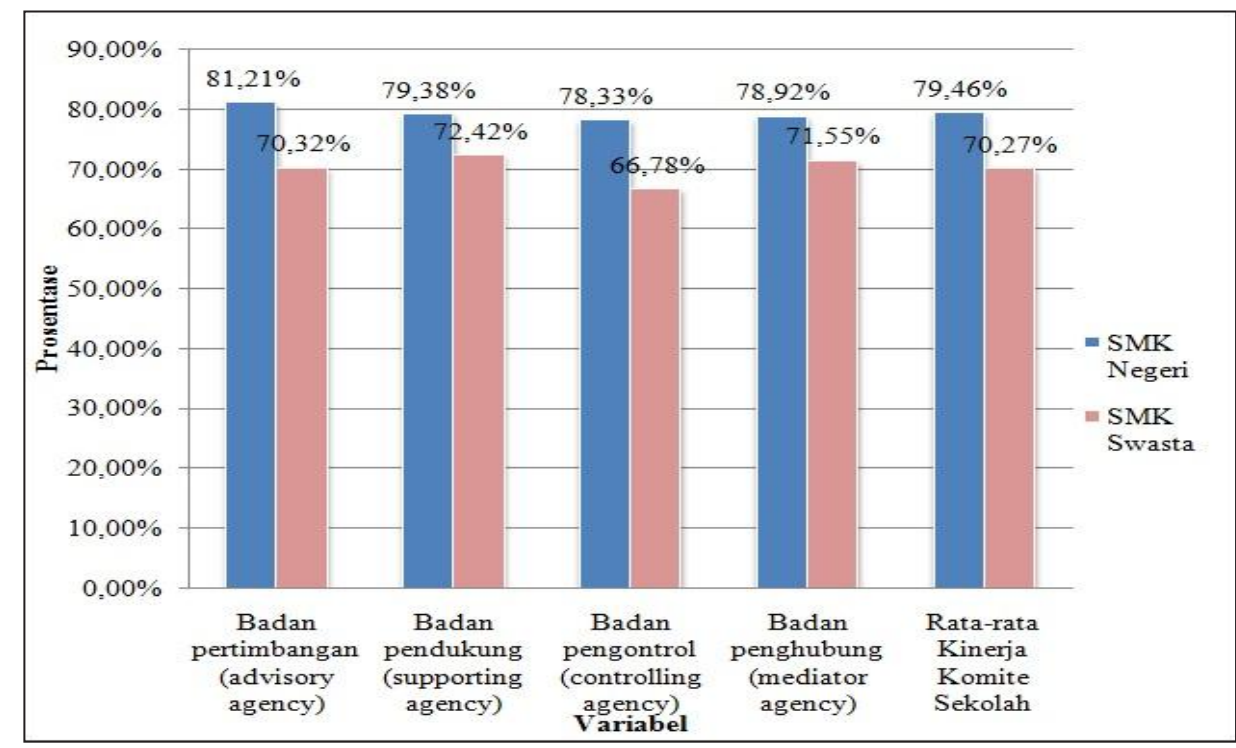

Gambar 3. Perbandingan Peran Komite Sekolah SMK Negeri dan SMK Swasta dalam penyelenggaraan pendidikan di Kabupaten Lamongan

Berdasarkan tabel 56 dan gambar 19 dapat dilihat perbandingan antara peran komite sekolah dalam penyelenggaraan pendidikan SMK negeri dan SMK swasta di Kabupaten Lamongan. Komite sekolah di SMK negeri menunjukkan skor rata-rata peran yang lebih tinggi yaitu sebesar 56,59 dengan prosentase $79,46 \%$, dibandingkan dengan rata-rata peran SMK swasta sebesar 50,02 dengan prosentase $71,27 \%$ dari skor maksimal. Variabel peran komite sekolah di SMK negeri yang paling menonjol adalah sebagai badan pertimbangan yang mempunyai skor rata-rata 56,84 dengan prosentase $81,21 \%$, kemudian sebagaibadan pendukung, badan penghubung, dan terakhir badan pengontrol. Variabel peran komite sekolah di SMK Swasta yang paling menonjol adalah sebagai badan pendukung yang mempunyai skor rata-rata 47,07 dengan prosentase $72,42 \%$, kemudian badan penghubung, badan pertimbangan, dan terakhir badan pengontrol. Kesamaan dari komite sekolah di SMK negeri dan swasta adalah lemahnya peran variabel badan pengontrol, sehingga memerlukan perhatian untuk ditingkatkan.

\section{SIMPULAN DAN SARAN}

\section{Simpulan}

Berdasarkan uraian tersebut, simpulan dari penelitian ini adalah sebagai berikut. (1) Peran komite sekolah dalam penyelenggaraan pendidikan SMK negeri secara keseluruhan termasuk dalam kategori baik. Peran yang paling tinggi adalah sebagai badan pertimbangan, kemudian sebagai badan pendukung, dan sebagai badan penghubung, sedangkan peran yang paling rendah adalah sebagai badan pengontrol. (2) Peran komite sekolah dalam penyelengga- 
raan pendidikan SMK swasta secara keseluruhan termasuk dalam kategori baik. Peran yang paling tinggi adalah sebagai badan pendukung, kemudian sebagai badan penghubung, dan sebagai badan pertimbangan, sedangkan peran yang paling rendah adalah sebagai badan pengontrol.

\section{Saran}

Berdasarkan simpulan di atas, maka saran dari penelitian ini adalah sebagai berikut. (1) kepada komite sekolah di SMK negeri agar mengadakan pelatihan untuk meningkatkan kualitas anggota komite sekolah dengan bekerja sama dengan dewan pendidikan dan dinas pendidikan kabupaten. Pelatihan tersebut diharapkan dapat meningkatkan peran komite sekolah dalam penyelenggaraan pendidikan di SMK, pelatihan juga ditekankan pada peran komite sekolah yang masih rendah yaitu sebagai badan penghubung dan badan pengontrol. (2) kepada komite sekolah di SMK swasta agar mengadakan pelatihan untuk meningkatkan kualitas anggota komite sekolah dengan bekerja sama dengan dewan pendidikan dan dinas pendidikan kabupaten. Pelatihan tersebut diharapkan dapat meningkatkan peran komite sekolah dalam penyelenggaraan pendidikan di SMK, pelatihan juga ditekankan pada peran komite sekolah yang masih rendah yaitu sebagai badan pertimbangan dan badan pengontrol. (3) kepada pihak sekolah agar lebih melibatkan komite sekolah dalam hal perencanaan program pendidikan, sehingga diharapkan komite sekolah dapat memberikan sumbangan pemikiran/pertimbangan dan tenaga dalam program pendidikan di sekolah. Komite sekolah yang dilibatkan secara penuh mulai dari perencanaan program akan sangat membantu tercapainya tujuan pendidikan dan kemajuan sekolah. (4) kepada pihak pemerintah dan dewan pendidikan agar menjalin komunikasi lebih aktif dengan pihak komite sekolah, sehingga komite sekolah mendapatkan perhatian dan dukungan dalam setiap menjalankan perannya. Pihak pemerintah dan dewan pendidikan agar melaksanakan pelatihan kepada anggota komite sekolah, sehingga dapat meningkatkan pengetahuan dan Peran anggota komite sekolah dalam penyelenggaraan pendidikan di sekolah khususnya di SMK. (5) kepada pihak peneliti perlu diadakan penelitian lebih mendalam tentang peran komite sekolah dengan menggunakan berbagai metode, sehingga memperoleh informasi yang lebih banyak. Penelitian juga bisa diperdalam dengan melakukan analisis komparatif atau perbandingan antara SMK negeri dengan SMK swasta. Selain itu, perlu diteliti juga mengenai peran komite sekolah sebagai badan pengontrol yang masih rendah dibandingkan dengan peran yang lain, apabila dilihat dari segi keanggotaan komite sekolah, latarbelakang pengurus, dan fasilitas yang tersedia bagi komite sekolah dalam menjalankan perannya.

\section{DAFTAR PUSTAKA}

Akinola, B.O. (2009). School based management committees: the Nigerian experience.The International Journal of Learning, 16(8), 421-430.

Sudijono, Anas. (2006). Pengantar evaluasi pendidikan. Jakarta: PT. Raja Grafindo Persada

Armansyah. (2009). Peranan dan pemberdayaan komite sekolah dalam penyelenggaraan pendidikan SMA Negeri di Kota Binjai. Tesis magister, tidak diterbitkan, Universitas Sumatra Utara. Medan

Boston Public School. (2013). The boston school committee. Diaksestanggal 29 Juli 2013, padahttp://www.bostonpublicschools.org/committee

Department of Education Newfoundland. (2008). Building learning communities: $a$ hand book for school council. Diakses tanggal 10 Mei 2014, padahttp:// www.ed.gov.nl.ca/edu/publications/k12/ Handbook2ndedition.pdf.

Depdiknas. (2002). Kepmendiknas Nomor 44/U/2002 tentang Dewan Pendidikan dan Komite Sekolah.

Depdiknas. (2003a). Acuan operasional dan indikator kinerja komite sekolah. Jakarta: Dirjen Pendidikan Dasar dan Menengah 
Depdiknas. (2003b). Undang-Undang RI Nomor 20, tahun 2003, tentang Sistem Pendidikan Nasional

Depdiknas. (2003c). Indikator kinerja dewan pendidikan dan komite sekolah. Jakarta: Depdiknas

Depdiknas. (2005). Peraturan Pemerintah Republik Indonesia Nomor 19 tahun 2005, tentang Standar Nasional Indonesia

Depdiknas. (2007). Pemberdayaan dewan dendidikan dan komite sekolah. Jakarta: Direktorat Jenderal Manajeman Pendidikan Dasar dan Menengah

Frontier School Division in Manitoba Canada. (2011). School committee resource manual. Manitoba : Frontier School Division.

Haryadi, Y., Meirawan, D., \& Rahadi, A. (2006). Pemberdayaan komite sekolah: modul 1: penguatan kelembagaan komite sekolah. Jakarta: Depdiknas

Hidayat, Nurdin. (2010). Peran komite sekolah dalam implementasi manajemen pendidikan di SMK N 4 Yogyakarta dan SMK Muhammadiyah 3 Yogyakarta. Tesis magister, tidak diterbitkan, Universitas Negeri Yogyakarta. Yogyakarta

Kemdikbud. (2013). Panduan penyusunan proposal bantuan sosial dewan pendidikan dan komite sekolah. Jakarta: Kemdikbud

Khan, M., et.al. (2013). Impact of school councils on head teachers' efficiency. Journal of educational research dept of education IUB Pakistan, 16(1), 15-26.

Kim A. (2004). Parent school partnership formation through the school council in Korea. Educational Research for Policy and Practice, 3, 127-139.
Alip, M \& Soenarto. (2008). Pelaksanaan peran komite sekolah dalam penyelenggaraan SMK di DIY. Jurnal Penelitian dan evaluasi Pendidikan, 1(11), 146 - 162.

Nurkolis. (2005). Manajemen berbasis sekolah. Jakarta: Grasindo

Nurlaela, L, et.al. (2011). Strategi peningkatan hubungan kemitraan antara komite sekolah, dunia usaha/dunia industri dengan sekolah menengah kejuruan. Jakarta: Direktorat Jenderal Pendidikan Menengah

Ontario Ministry of Education. (2002). School councils: a guide for members. Ontario: Ontario Ministry of Education

Osorio, B, et.al. (2009). Decentralized decision-making in schools the theory and evidence on school-based management. Washington DC: The World Bank.

Slamet. (2005, Januari). Pengembangan Kapasitas untuk Mendukung Desentralisasi Pendidikan Kejuruan. Pidato Pengukuhan Guru Besar pada Rapat Terbuka Senat di Universitas Negeri Yogyakarta

Suparlan, Tumenggung, A., \& Meirawan, D. (2006). Pemberdayaan komitesSekolah: modul 3 peningkatan wawasan kependidikan pengurus komite sekolah. Jakarta: Depdiknas

Zajda, J. (2009). Decentralisation, schoolbased management, and quality. New York: Springer 